\title{
Zwischen Christentum und Staatsraison. Römisches Imperium und religiöse Gewalt ${ }^{*}$
}

\author{
ULRICH GOTTER
}

Im Jahre 388 kam es in Kallinikon am Euphrat, als man gerade das Fest der Makkabäischen Brüder beging, zu Ausschreitungen. Was damals genau und in welcher Reihenfolge geschah, ist leider alles andere als transparent. Sicher erscheint immerhin, daß der dortige Bischof Mönche zur Gewaltanwendung angestiftet, den städtischen Mob mobilisiert und auf die Kultplätze Andersgläubiger losgelassen hat. Das Ergebnis waren Krawalle sowie der Brand der örtlichen Synagoge und eines Konventikels der Valentinianer, einer gnostischen Sekte. ${ }^{1}$ Der Zeitpunkt für die Aktion war gut gewählt und wohl kaum vom Zufall diktiert: Die ,Makkabäischen Brüder` waren, gemäß der Überlieferung, jüdische Märtyrer aus dem Makkabäerkrieg, deren wichtigste Verehrungsstätte die Christen von Antiocheia wohl kurz zuvor der jüdischen Gemeinde entwunden hatten. ${ }^{2}$

Da es sich unbestreitbar um kollektive Gewaltanwendung handelte, zog der Vorfall rasch größere Kreise. Die Angelegenheit wurde vor dem Comes Orientis verhandelt, der sie wegen ihrer Brisanz dem Kaiser vorlegte. ${ }^{3}$ Daraufhin verfügte Theodosius I., der zu diesem Zeitpunkt in Italien weilte, in einem Edikt zweierlei: Zum einem sollten die kriminellen Mönche wegen Gewaltanwendung bestraft

1 Das Geschehen in seinen einzelnen Aspekten ist nahezu ausschließlich aus den interessegeleiteten Argumenten des Ambrosius in einem Brief an Theodosius I. sowie einem an seine Schwester zu rekonstruieren: Ambr. epist. 74 (40),6 (epist. extr. coll. 1a,6; zum zeitlichen Verhältnis von epist. 74 und epist. extr. coll 1a vgl. GROß-ALBENHAUSEN 1999, 100-101); 74 (40),8; 74 (40),13-14; 74 (40),16; epist. extr. coll. 1 (41),1. Zur Kallinikon-Affäre s. v.a. KolB 1980, 46-48; MCLYNN 1994, 298-309; GROß-ALBENHAUSEN 1999, 99-112 (letztere ist allerdings sehr wenig analytisch).

$2 \mathrm{Zu}$ den Auseinandersetzungen zwischen Christen und Juden in Antiocheia und der Übernahme der Grabstätte der makkabäischen Märtyrer durch die christliche Gemeinde HAHN 2004, 180189.

3 Ambr. epist. 74 (40),6. Mit der Bemerkung, daß noch kein Bericht des Bischofs von Kallinikon vorlag, als der Comes Orientis bereits seine Darstellung an den Kaiser gesandt hatte, betont Ambrosius die hohe Geschwindigkeit, mit der die Affäre auf die höchste Ebene transferiert wurde. Mit welcher Intention der Comes, wohl ein dezidierter Christ (zur Identifizierung FowDEN 1978, 67), hier gehandelt hat, wird allerdings nicht ganz klar. MCLYNN 1994, 299 n. 27 insinuiert einen möglichen Konflikt mit dem Präfekten von Konstantinopel, dem erklärten Nichtchristen Eutolmios Tatianos. Wahrscheinlich ist aber eher, daß der Comes nicht selbständig handeln wollte, weil ihm völlig klar war, was dann von ihm erwartet würde (s.u. n. 5). 
werden, zum anderen der Bischof - als Anstifter - die zerstörte Synagoge aus den Mitteln der christlichen Kirche wiederherstellen. ${ }^{4}$ Im Lichte der imperialen Ordnung erscheint dieses Urteil ebenso fair wie moderat, und insbesondere der Bischof von Kallinikon war dabei eigentlich gut weggekommen. Immerhin hatte er einen gewaltsamen Konflikt vom Zaun gebrochen, der die Ordnung zeitweilig außer Kraft setzte und die Bevölkerung seiner Stadt spaltete. ${ }^{5}$ Eine gewissermaßen rein zivilrechtliche Schadensersatzleistung konnte man bei dieser Sachlage eigentlich nur als Akt kaiserlicher clementia verstehen.

Das sah man allerdings im Kreis der Bischöfe des Reiches ganz anders. Dort sorgte das kaiserliche Edikt für beträchtliche Unruhe, und Ambrosius, dem Bischof von Mailand, fiel die Rolle zu, den Kaiser in die Schranken zu fordern. ${ }^{6} \mathrm{Er}$ sprach erst bei Theodosius vor und richtete dann eine briefliche Demarche an ihn, die an Deutlichkeit sogar sein späteres Ermahnungsschreiben wegen des Massakers in Thessalonike in den Schatten stellte. ${ }^{7}$ Als der Kaiser kurz darauf einen von Ambrosius in Aquileia geleiteten Gottesdienst besuchte, predigte der Bischof ostentativ gegen die Juden und warnte deren Parteigänger. ${ }^{8}$ Und noch in der Kirche, vor der Wandlung, kam es zwischen Gottesmann und Kaiser zur abschlieBenden Verhandlung der leidigen Affäre. Dabei war zwar Theodosius rasch bereit, dem Bischof von Kallinikon den Wiederaufbau der Synagoge zu erlassen; doch bestand er auf der Bestrafung der Mönche. Sie seien, so der Kaiser, nun einmal notorische Kriminelle. ${ }^{9}$ Ambrosius dagegen verlangte die vollständige Niederschlagung des Verfahrens gegen alle Beteiligte. Als Entscheidungshilfe verweigerte er dem Kaiser die Kommunion, bis dieser ihm ein förmliches und öffentliches Versprechen gegeben hatte. Theodosius' Nachgeben kommentierte Ambrosius in einem Brief an seine Schwester schließlich triumphierend mit der Bemerkung: „Und so geschah alles, wie ich es mir wünschte.“10

Aus der Perspektive des Imperiums war dieses Ende der Angelegenheit hingegen alles andere als befriedigend. Zwar hatte sich Theodosius am Ende gegen-

4 Ambr. epist. 74 (40),6; 74 (40),9-10; epist. extr. coll. 1 (41),1.

5 Für wie selbstverständlich Theodosius das Handeln der Administration in dieser Sache ansah, beweist seine explizite Ungehaltenheit darüber, daß der Comes Orientis, statt einfach die Schuldigen zur Rechenschaft zu ziehen, den Fall an den Kaiser weiterleitete (Ambr. epist. 74 (40),18).

6 MCLYNN 1994, 302.

7 Zum persönlichen Gespräch des Bischofs mit dem Kaiser: Ambr. epist. 74 (40),8-9. Für den Vergleich mit der Thessaloniki-Affäre s. Ambrosius' Brief an den Kaiser (epist. 11 (51)), der anders als in der causa Kallinikon - stärker von milder Trauer als von scharfem Vorwurf geprägt war. Auch daß sich der Bischof in der Einleitung von epist. 74 (40) veranlaßt sieht, die Parrhesia des Kirchenmannes gegenüber dem gerechten und rechtgläubigen Herrscher zu reklamieren, spricht für die exzeptionelle Deutlichkeit, mit der hier gesprochen werden sollte.

8 Ambr. epist. extr. coll. 1 (41),12-26 (an seine Schwester).

9 Ambr. epist. extr. coll. 1 (41),27.

10 Ambr. epist. extr. coll. 1 (41),28 (Übers. U. Gotter). 
über der Gemeinde von Aquileia als frommer Christ gezeigt, ${ }^{11}$ doch die öffentliche Revokation eines Edikts kann sein Prestige kaum gesteigert haben. Schlimmer noch war der Schaden für die Kalkulierbarkeit administrativen Handelns und den Glauben an die Geltung des Rechts. In einer Stadt des Reiches hatte es gewaltsame Ausschreitungen gegeben, man kannte die Anstifter und Akteure - und doch gingen alle straflos aus. Die Opfer wurden nicht einmal kompensiert, es gab keine symbolischen Akte der Reue, und sogar Maßnahmen zum Schutz vor ähnlichen Vorkommnissen blieben aus. Kurz: In der Affäre von Kallinikon hatte die Administration mit einem geheiligten Prinzip des römischen Staates gebrochen. Zwar basierte die römische Ordnung nicht auf der gleichmäßigen Durchsetzung uniformer Normen, ${ }^{12}$ wohl aber auf der strikten Ächtung von Gewalt als Mittel des Konflikts. ${ }^{13}$ Wo immer dergleichen auftrat, war nach traditioneller Auffassung die Grenze von Selbstbestimmung zu seditio, Aufruhr, überschritten. Und Aufruhr forderte im Grunde unweigerlich die Machtmittel des Imperiums heraus.

Vor diesem Hintergrund könnte man die Ereignisse von 388 n.Chr. durchaus als imperiale Katastrophe bezeichnen, wenn sie nicht nur die Spitze des Eisbergs gewesen wären. Denn was in Kallinikon und Aquileia geschah, war nicht das Ergebnis einer singulären persönlichen Konstellation, in der ein außergewöhnlicher Bischof einem bestimmten Kaiser heroisch die Sonderbehandlung seiner Klientel abtrotzte. Die Prominenz der Beteiligten und die Dramatik des Duells im Gotteshaus sorgten allenfalls dafür, daß wir über das Geschehen vergleichsweise gut informiert sind. ${ }^{14}$ Gewalt gegen jüdische Kultplätze und Gemeinden indessen war kein Einzelfall. Ebenfalls im Jahr 388, kurz vor dem Aufruhr in Kallinikon,

11 MCLYNN (1994, 308) spielt das Ergebnis der Konfrontation für den Kaiser systematisch und gegen die ältere Forschung herunter: „,The loser in this unhappy affair was Ambrose. Theodosius had been forced to concede clemency in a case he felt deserved exemplary punishment; but such concessions were an occupational hazard of the imperial office. As a compensation, moreover, he could enjoy the gratitude and admiration which he had no doubt inspired among the Christians of Milan. The bishop, however, had failed entirely to win the emperor's sympathy". Diese Sichtweise mag für die situative Kommunikationssituation der beiden Protagonisten nicht völlig unberechtigt sein - bereits KOLB 1980, 63-64 hat für die Beilegung der Kallinikon-Affäre und den Bußakt von Mailand den Zugewinn des Kaisers an Demutskapital hervorgehoben -, doch stellt sich die Sache für den zweiten Köper des Herrschers, seine imperiale persona, nicht ebenso einfach dar. Aus dieser Perspektive konnte der Verlust an Ordnung nicht durch die Demonstration von Frömmigkeit kompensiert werden.

12 Dies betonen die neueren Studien und synthetischen Darstellungen zum Imperium Romanum nahezu unisono: beispielhaft und explizit s. etwa MATTINGLY 1997; BARRETT 1997. Zu den primären und in der Tat gleichartigen Instrumenten zur Herstellung von akzeptierter Ordnung vgl. allerdings WHITTAKER 1997.

13 LENDON 1997, 2-7.

14 Dies hängt vor allem mit der Konservierung der entsprechenden Briefe im Corpus der Ambrosius-Werke zusammen. 
war eine Synagoge in Rom in Flammen aufgegangen $;{ }^{15}$ weitere Angriffe gab es in den letzten Dezennien des 4. und zu Beginn des 5. Jahrhunderts. ${ }^{16}$

Dennoch träfe es nicht den Kern, diese Ereignisse unter dem Lemma eines wachsenden Antijudaismus oder Antisemitismus einzuordnen. ${ }^{17}$ Das legt eigentlich schon das Geschehen in Kallinikon selbst nahe. Denn die Juden waren keineswegs die einzigen Leidtragenden von Gewalt gegen Kultstätten. Seit der Mitte des 4. Jahrhunderts kam es immer wieder zu Übergriffen auf pagane Heiligtümer, ${ }^{18}$ ähnliches gilt für kleinere religiöse Gruppierungen wie Samaritaner, Valentinianer und Manichäer. ${ }^{19}$ Und selbst christliche Kirchen der falschen Ausrichtung oder des falschen Bischofs blieben von gewaltsamen Übernahmen und plötzlichem Brand nicht verschont. ${ }^{20} \mathrm{Da}$ es dabei unweigerlich auch zu Personenschäden kam, bedarf nicht der Erwähnung. Die dezentrale und illegale ${ }^{21}$ Gewaltausübung gegen Kultorte, Kultgruppen und ihre Riten war also längst zu einem Phänomen geworden, das das politische Klima im Reich umfassend prägte und in den folgenden Jahrzehnten noch eine bedeutende Karriere vor sich hatte. ${ }^{22}$ Unter diesen Umständen demonstriert die Kallinikon-Affäre lediglich besonders eindrucksvoll die Ohnmacht des spätantiken Staates, die traditionellen Normen des Imperiums durchzusetzen. Daß den Beteiligten dieses Problem auch durchaus erkennbar war, zeigt die Reaktion des Theodosius, der sich die Bestrafung der Schuldigen zunächst nicht vollständig abhandeln lassen wollte.

Im folgenden will ich einerseits nach Gründen für diese Ohnmacht fragen und andererseits präziser zu umreißen versuchen, was die Gewaltanwendung zwischen religiösen Gruppen für die politische Kultur des Reiches bedeutete. Dazu soll in einem ersten Schritt rekapituliert werden, über welche Mechanismen zur Unterdrückung von Gewalt der kaiserzeitliche Staat verfügte und warum diese so erfolgreich waren. Sodann wird - gewissermaßen als Gegenprobe - mit einem

15 Ambr. epist. 74 (40),23; s. NoETHLichs 1971, 184-185. Für die Umwandlung der Synagoge von Apameia in eine christliche Kirche und die antijüdischen Kontexte dieses Vorgehens vgl. BRENK 1991.

16 Bekannt sind insbesondere die Aktionen des Mönches Barsauma in Syrien, das, wie BRENK 1991, v.a. 14-19; 22-24 gezeigt hat, ein regionaler Schwerpunkt für die Zerstörung bzw. Umwandlung von Synagogen in Kirchen war; s.a. STEMBERGER 1987, 247-249; MiTCHELL 1999, 234-238

17 So etwa SAFRAI 1994, 435-436.

18 Dazu jetzt HAHN - EMMEL - GOTTER 2008. Eine breite Fallsammlung findet sich bereits bei TROMBLEY 1993/1994; s.a. HAHN 2004, v.a. 191-270.

19 NOETHLICHS 1986, 1180-1182; STEMBERGER 1987, 182.

20 GADDIS 2005, 79-88; HAHN 2004, 48-77; ISELE 2008.

21 Kaiser Maximus ächtete in einem Edikt das gewaltsame Vorgehen gegen jüdische Kultorte und drohte dafür wohl schwere Strafen an (vgl. NOETHLICHS 1971, 182-188). Zum Rechtsstatus der Juden im Reich s. RABELLO 1980, der seinerseits auf dem umfassenden Werk JUSTERS 1914 beruht; zum Schutz der jüdischen Kultorte im 4. und 5. Jahrhundert JUSTER 1914, Bd. 1, 460472; LINDER 1987, 85-86; BRENK 1991, 12-14.

22 Vgl. TROMBLEY 1993/1994; zur Rolle der Bischöfe dabei FowDEN 1978. 
Blick auf den ersten jüdischen Aufstand gezeigt werden, unter welchen Bedingen diese imperialen Mechanismen nicht funktionierten, bevor ich in einem dritten Abschnitt auf Kallinikon, die Dysfunktionalität der traditionellen imperialen Normen unter christlichen Auspizien und die Konsequenzen des Prozesses zurückkomme.

\section{Kaiserzeitliches Gewaltmanagement}

Womöglich war das Imperium Romanum gerade deshalb so effizient, weil es nicht versuchte, Konflikte unter den Beherrschten wirklich zu lösen bzw. dauerhaft auszuräumen. ${ }^{23}$ Das nämlich hätte positive sachliche Zielvorgaben verlangt, eine materielle Definition von Ordnung und eine flächendeckende Festlegung von Normen, die angesichts der enormen kulturellen und politischen Differenzen innerhalb des Reiches niemals einen stabilen Konsens generiert hätten. Statt dessen begnügte man sich mit der Setzung von institutionellen Rahmenbedingungen, innerhalb derer die subsidiären, regionalen politischen Organisationsformen zumindest partiell intakt bleiben konnten. Als ordnungspolitisches Gegengewicht forderte diese administrative Minimallösung aus römischer Perspektive allerdings zumindest, die Austragung von Konflikten zu reglementieren bzw. zu entschärfen. Konkret bedeutete das schlichtweg die Ächtung von kollektiver und individueller Gewaltanwendung auf lokaler Ebene. ${ }^{24}$ Bei aller Autonomie der subsidiären Einheiten machte die Zentrale unmißverständlich klar, daß der Einsatz von Gewalt den Eingriff der Institutionen des Reiches provozierte. Das galt natürlich in erster Linie für die Zusammenrottung von Gruppen, die die Funktion von lokalen Gemeinschaften unmittelbar bedrohten oder sich gar gegen die römische Ordnung auf Provinzebene richteten. Bezeichnend ist aber, daß auch die kriminelle Gewaltanwendung durch den Einzelnen, wenn sie eine Kapitalstrafe erwarten ließ, die Reaktion der Zentralmacht regelhaft provozierte. In diesen Fällen wurde die Rechtsprechung und Ahndung des Verbrechens der lokalen Einheit entzogen und den Institutionen der Reichsverwaltung überantwortet: ${ }^{25}$ Auch die äußerste legale Gewalt war damit zumindest idealerweise monopolisiert.

23 Vgl. treffend WolfF 1999, 60: „Es scheint mir ein (...) Geheimnis des Erfolges römischer Reichspolitik wie auch der Reichsadministration gewesen zu sein, daß sie beide nicht auf positive Utopien festgelegt waren, sondern solche Vorgaben nur sehr allgemein und vor allem negativ formulierten."

24 DAHLHEIM 2003, 100-114; 237-239; JACQUES - SCHEID 1998, 192-198; ECK 1999; MITCHELL 1999, 25-29; BLEICKEN 1978, Bd. 1, 130-132.

25 NÖRR 1966, 32-33 (zu Regel und Ausnahme); GARNSEY 1968, 51-55; STAHL 1978, 90-99; JACQUES - SCHEID 1998, 197; JÖRDENS 1999, 154; 163-164 (für Ägypten); HORSTKOTTE 1999, 309-310; 313; zu den Ausnahmen: 307. NÖRR 1999, 261-262 betont das Mißtrauen der Griechen gegenüber ihrer eigenen „Gerechtigkeit“. 
Diese Regelung war hochgradig funktional und traf präzise den Nerv des Problems. Vor allem die östlichen griechischen bzw. hellenisierten Polisgesellschaften waren hochkompetitive Einheiten, die zu existentiellen Konflikten mit latenter Bürgerkriegstendenz neigten. Im Zentrum dieser Auseinandersetzungen standen Cliquen, die erhebliche Teile der Bürgerschaft über meist binäre Optionen mobilisieren konnten. ${ }^{26}$ Klassisch in diesem Sinne war die Antithese von Demokraten und Oligarchen, von ,Armen' und ,Reichen', später von Romfreunden und Romfeinden. Auf den sachlichen Gehalt dieser Auseinandersetzungen kam es dabei allerdings nicht in erster Linie an: Im Prinzip taugte jede bedeutsame Entscheidung für die Organisation von lokalen Konflikten. ${ }^{27}$ Und einerlei nach welchen ideologischen Positionen sie sich entfalteten - Mitglieder der Führungsschicht waren auf beiden Seiten tonangebend, selbst im Rahmen der angeblich sozialen Auseinandersetzungen.

Für die Schärfe ihrer Austragung indessen war die Gewaltfrage von entscheidender Bedeutung. Die enorme zentrifugale Wirkung von Gewaltakten im griechischen Kontext hängt wohl vor allem damit zusammen, daß Gewalt dort außerordentlich zeichenhaft und aufs engste mit dem politischen Zentralbegriff der Macht verknüpft war. So erschöpfte sich Gewaltanwendung aus der Perspektive der Beteiligten nicht im physischen Akt und seinen unmittelbaren Konsequenzen, sondern verkörperte darüber hinaus gleichzeitig einen Anspruch von größerer Reichweite. Wer es sich leisten konnte, einen oder mehrere andere zu schlagen, $\mathrm{zu}$ verletzen oder zu töten, reklamierte damit gleichzeitig Vorrang und Übermacht. ${ }^{28}$ Hinter dieser Wahrnehmung lauerte die Gefahr, daß auch die sehr partikulare, gewissermaßen private Gewaltanwendung rasch ins Kollektive abglitt und schließlich in äußerster Eskalation endete. Im griechischen Osten schuf, oder besser: zementierte Gewalt schnell Parteiungen.9 Die grundsätzliche Konfliktkonstellation in den Poleis überlebte auch die politischen Veränderungen während des Hellenismus und der römischen Kaiserzeit. ${ }^{30} \mathrm{Da}$ man sich auf römischer Seite der Latenz eines zentrifugalen Parteienwesens durchaus bewußt war, zeigt etwa die strikte Weigerung Trajans, ein pragmatisch gebotenes FeuerwehrCollegium in Nikaia zuzulassen: „Du bist auf den Gedanken gekommen, man könne nach dem Vorbild mehrerer anderer Städte in Nikomedia eine Handwerkergilde bilden. Aber vergessen wir doch nicht, daß deine Provinz und vornehmlich

$26 \mathrm{Zu}$ den Prinzipien des inneren Krieges in Griechenland vgl. v.a. GEHRKE 1985, 205-353; zur Bipolarität der Konflikte GEHRKE 1985, 245-249; s.a. CARTLEDGE 1993, 111-114.

27 DEININGER 1971, 12-20; GEHRKE 1985, 309-353.

28 S. TRAMPEDACH 2006, mit dem Hinweis auf die latente Attraktivität der Tyrannis.

29 Zum entsprechenden Muster, das sich um das Motiv der Rache organisiert, GEHRKE 1987, 130$136 ; 144-145$.

30 Zur Existenz von Auseinandersetzungen in den griechischen Städten des Hellenismus und der Kaiserzeit: SARTRE/SARTRE 2000; BENCIVENNI 2003; DösSEL 2003. Eine systematische Analyse der Konfliktkonstellationen und Stasisphänomene nach dem 4. Jhdt. v. Chr. bleibt jedoch ein unbedingtes Desiderat der Forschung. 
ihre Gemeinden unter derartigen Organisationen zu leiden gehabt haben. Einerlei, aus welchem Grunde wir sie zulassen, und welchen Namen wir den Leuten geben, die für einen bestimmten Zweck organisiert werden, es werden immer, und zwar in ganz kurzer Zeit, Hetärien daraus werden“. 31

Unter diesen Umständen war es ein weitsichtiger Akt der römischen Administration, die Regelung gewaltsamer Konflikte und die Ahndung von Gewalttaten dem lokalen Biotop vollständig zu entziehen. Denn erfahrungsgemäß konnten selbst ordentliche Gerichtsurteile auf der Ebene städtischer Gemeinschaften nur schwer das akzeptanzvernichtende Stigma der Parteilichkeit vermeiden. ${ }^{32}$ Mit dem Prinzip der systematischen Entfernung des Urteils über Gewalttaten von ihrem Schauplatz - dabei galt die Faustregel: je bedeutender die Beteiligten, desto höher die richtende Instanz ${ }^{33}$ - vermochte Rom dagegen eine glaubhafte Position der Neutralität einzunehmen. Diese Neutralität erstreckte sich auch vor allem auf die Begründung für Gewaltanwendung. Gewalt selbst war der entscheidende Tatbestand, der geahndet wurde, nicht das Motiv hinter der Gewalt. Aus der Perspektive der Reichsverwaltung waren der Grund und die Begründung für Gewaltanwendung nebensächlich.

Berücksichtigt man die besondere kulturelle Disposition der östlichen Gemeinschaften, erscheinen Distanz und Neutralität als die zentralen Instrumente der pax Romana. Der Gewalt, des wichtigsten Katalysators von Bürgerkriegen beraubt, waren die östlichen Eliten zur zumindest zähneknirschenden Kooperation gezwungen.

Was aber garantierte die Akzeptanz eines römischen Diktats, das immerhin tief in kulturelle Verhaltensweisen eingriff und das politische Klima im römischen Osten grundlegend verwandelte? Kurioserweise war hierfür wohl gerade derjenige Zug griechischer politischer Wahrnehmung entscheidend, der auf lokaler Basis eine zentrifugale Wirkung entfaltete: die Obsession für das Argument der Macht. ${ }^{34}$ Entscheidend war dabei nicht unbedingt die tatsächliche Macht des römischen Imperiums, also gewissermaßen die Pistole an der Schläfe der Akteure, sondern die Wahrnehmung Roms als unüberwindlich. Dieses Dogma hatte sich in einem schmerzhaften und von brennenden Städten gesäumten Lernprozeß tief in das griechische Weltverständnis eingegraben. ${ }^{35}$ Gewohnt, die Welt als ein

31 Plin. epist. 10,34,1: tibi quidem secundum exempla complurium in mentem venit posse collegium fabrorum apud Nicomedenses constitui. sed meminerimus provinciam istam et praecipue eas civitates eius modi factionibus esse vexatas. quodcumque nomen ex quacumque causa dederimus iis, qui in idem contracti fuerint, hetaeriae eaeque brevi fient (Übers. $\mathrm{H}$. Kasten). Zum römischen Mißtrauen gegen das Vereinswesen zuletzt BENDLIN 2005.

32 Zu Losverfahren und Bestechungsverdacht s. HANSEN 1991, 204-205; GEHRKE 1985, 208-210; DÖSSEL 2003, 277.

33 JACQUES - SCHEID 1998, 197; STAHL 1978, 148-158; HORSTKOTTE 1999, 305-306. Zur sozialen Ausdifferenzierung des Rechtsapparats vgl. RILINGER 1988.

34 Hierzu jetzt GOTTER 2008, 183-199.

35 DEININGER 1971, 191-261; 269-270; GEHRKE 2003, 122-131; 227-230. 
System von Machtbeziehungen zu analysieren, erschien letzten Endes die Unterordnung unter fremde Prinzipien zwar nicht gerade als begrüßenswert, doch immerhin als plausibel, wenn sich an der Übermacht des anderen nun einmal nichts ändern ließ ${ }^{36}$

Diese Kapitulation vor dem Unvermeidbaren bringt Plutarch in seinen Praecepta gerendae rei publicae auf den Punkt, wenn er im 2. Jahrhundert n. Chr. den zeitgenössischen griechischen Polisaristokraten folgenden politischen Imperativ verordnet:

„Und wenn du irgendein Amt übernimmst, mußt du dir nicht nur die Maximen ins Gedächtnis rufen, die Perikles memoriert hat, als er den Mantel eines Generals anlegte: ,Denk daran, Perikles, du beherrschst freie Männer, Griechen beherrschst du, athenische Bürger', sondern du mußt dir auch sagen: ,Du herrschst über eine Stadt als ein Beherrschter, kontrolliert von Prokonsuln, den Agenten des Kaisers. (...) Du solltest also deinen Mantel aufmerksamer arrangieren und vom Amt des Generals weg auf die Redebühne schauen und nicht deine Krone so hochschätzen und ihr vertrauen, wo du doch den Stiefel des römischen Soldaten direkt über deinem Kopf siehst. Vielmehr sollst du die Schauspieler nachahmen, die in ihre Rolle das eigene Pathos, den eigenen Charakter und die eigene Würde legen, doch auf den Souffleur hören und in Reimen und Versmaß nicht die Freiheit überschreiten, die ihnen von den über sie Herrschenden eingeräumt wird. “37

Selbst wenn also die Ansprüche des Imperiums mit den eigenen kollidieren sollten oder die Normen des Imperiums im Grunde nicht akzeptabel sein mochten, ${ }^{38}$ galt doch der Grundsatz, daß man gegen die Übermacht des Diktats nichts Erfolgversprechendes ausrichten konnte. Auf diese Weise war die Aura der Unbesiegbarkeit des Imperiums der rocher de bronze, auf dem die Akzeptanz der römischen Ordnung im griechischen Osten ruhte.

36 Der Topos von der Unbesiegbarkeit Roms beherrscht den griechischen intellektuellen Diskurs über Rom seit Polybios: DAHLHEIM 2003, 111f; DEININGER 1971, 270-273.

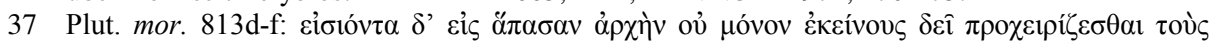

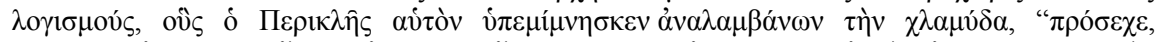

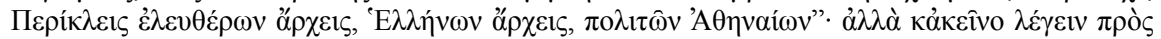

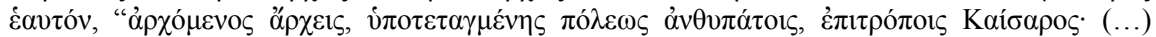

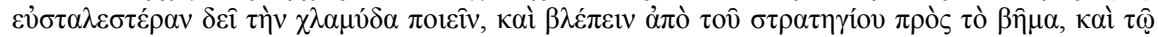

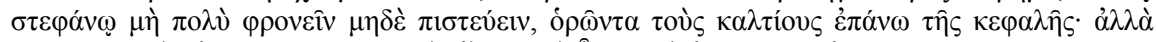

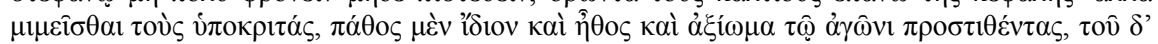

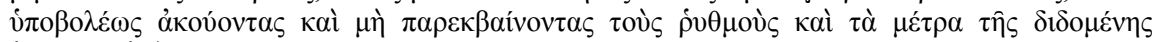

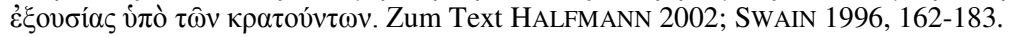

38 So beklagt Plutarch (798C-806B), daß eine heroische aristokratische Profilbildung (die Blutvergießen zwingend beinhaltete) durch das römische Diktat unmöglich gemacht worden sei. Statt dessen seien nur noch Talente gefragt, die auf friedliche Konkurrenz abzielten. Aelius Aristides formuliert übrigens denselben Tatbestand, bewertet ihn allerdings ausschließlich positiv (Ael. 68-69; 96-99). Gegenüber dieser Friedhofsruhe (824C-D) scheint in Plutarchs Text die Sehnsucht nach existenziellen Konflikten auf (s. HALFMANN 2002, 87-92). SwaIN (1996, 171) faßt die Haltung des Mannes aus Chaironeia folgendermaßen zusammen: „His own advice is to stay at home and, in brief, not to integrate“. 


\section{Gegenprobe: Die Grenzen der römischen Ordnung}

Die Propagierung des übermächtigen Imperiums war nahezu überall erfolgreich. Es gab allerdings eine Ausnahme, und diese ist heuristisch außerordentlich wertvoll. Denn sie bestätigt einerseits den Befund und zeigt andererseits präzise an, wo die Grenzen des römischen Herrschaftssystems lagen. War die Akzeptanz der römischen Ordnung im östlichen Mittelmeerraum insgesamt stabil, galt dies nicht für Judäa im ersten und zweiten Jahrhundert $\mathrm{n}$. $\mathrm{Chr}^{39}$ Eine Integration in das Imperium gelang dort nur sehr rudimentär: So rückten anders als in den anderen östlichen Provinzen Angehörige der jüdischen Oberschicht nicht in die Funktionseliten des Reiches auf. Zwar gab es auch jüdische Angehörige des ordo equester, des reichsrömischen Ritterstandes, doch blieb dies ein Phänomen des sozialen Status. Denn die Übernahme von Ämtern, die eigentlich mit dem Ritterrang verbunden war, hätte die Ausübung religiöser Kulte bedeutet, die einem Juden verboten war. ${ }^{40}$ Ein Angehöriger der jüdischen Führungsschicht hatte also regelmäßig zwischen einer administrativen Karriere und der Zugehörigkeit zu seiner traditionellen Religionsgemeinschaft zu wählen. ${ }^{41}$ Damit war für den jüdischen Fall die Einbindung regionaler Oberschichten in den imperialen Apparat ausgeschlossen, und der römischen Herrschaft in Judäa fehlte ein wesentlicher Transmissionsriemen. Daß dies insbesondere im Rahmen eines Ordnungssystems problematisch war, das seit Jahrhunderten darauf fixiert war, regionale Integration über die Einbindung indigener Führungseliten herbeizuführen, liegt auf der Hand. Die funktionale Abstinenz der jüdischen Oberschicht machte sich in den Eskalationen im Judäa des ersten nachchristlichen Jahrhunderts außerordentlich negativ bemerkbar. Während etwa die übrigen Bewohner Palästinas und Syriens Vertreter

39 Zu den Konflikten zwischen Juden und Römern in Judäa: BALTRUSCH 2002, 129-147; HENGEL 1976; HENGEL 1999, 149-152; WILKER 2007, v.a. 377-470. Dagegen weist GOODMAN 1991 auf die seiner Meinung nach geringe Evidenz für eine allgemeine Ablehnung der römischen Herrschaft in Judäa hin. Entscheidend ist allerdings, daß für die zelotische Position, auch wenn sie zahlenmäßig in der Minderheit gewesen sein mag, mit der Schrift eine mächtige Option eines Anti-Diskurses zur Verfügung stand, der, wenn es sich anbot, im jüdischen Kontext wirksamer aktualisiert werden konnte als andernorts. In seinem Bemühen, die Besonderheit der judäischen Verhältnisse zu negieren, verzerrt Goodman zunächst die Evidenz, indem er Grenzgebiete mit Regionen im Herzen des Imperiums vermengt (225-230). Seine Position, daß das Reich insgesamt lediglich durch uniforme konstante Furcht zusammengehalten worden wäre (236-237), ist ebenso holzschnittartig wie soziologiefern. Geradezu absurd ist die These, daß auch bei den anderen Aufständen im Reich die religiöse Mobilisierung relevant gewesen sei (237-238). Hier überschätzt Goodman die Möglichkeit des Polytheismus bei weitem, Konflikte über Kultgruppen zu generieren.

40 JUSTER 1914, Bd. 2, 243-244; 248-249.

41 Ein bezeichnendes Beispiel dafür ist Tiberius Alexander, der Befehlshaber der ägyptischen Legionen, die 69 n. Chr. Vespasian zum Kaiser ausriefen: Von jüdischer Herkunft, opferte er seine Zugehörigkeit zum aktiven Judentum einer steilen Militärkarriere (s. JUSTER 1914, Bd 2; 249 n. 3 und 4$)$. 
ihres Ethnos im administrativen Apparat hatten - in der Regel Figuren, die meist keine Sympathien für die Juden hegten ${ }^{42}-$, gab es auf jüdischer Seite dazu kein Gegengewicht.

Die Integration Judäas in das Imperium war allerdings nicht nur wegen mangelnder funktionaler Repräsentation seiner Oberschicht fragil. Auch die prinzipielle Beugung unter die römische Macht war nicht dauerhaft konsensfähig. Daß das ordnungsvermittelnde Standardargument, die Unbesiegbarkeit des Imperiums, in Judäa nicht zog, war für Flavius Josephus, den jüdischen Historiker und Augenzeugen des großen Aufstandes, jedenfalls bemerkenswert genug, um darin eine wesentliche Erklärung für die Eskalation des Konflikts mit Rom zu sehen. In seinem Werk über den ,Jüdischen Krieg' macht er aus dem Thema eine Schlüsselszene für den Weg der Juden in die militärische Katastrophe. Der König des nördlichen Palästina und Aufseher über den Jerusalemer Tempel, Agrippa II., versucht seine Landsleute durch eine Rede vom Waffengang abzuhalten und zur Umkehr zu bewegen. Bezeichnenderweise läßt ihn Josephus nicht in erster Linie über Recht und Unrecht diskutieren, sondern über (macht)politische Opportunitäten:

„Ihr, die ihr schon das Gehorchen als Erbschaft empfangen habt, und in euren Hilfsmitteln jenen, die als erste diesen Gehorsam auf sich nahmen, so weit unterlegen seid, ihr wollt der römischen Gesamtstreitmacht Widerstand leisten? Schaut die Athener an, die einst um der Freiheit der Griechen willen ihre Stadt sogar dem Feuer preisgaben. (...) Sie, die bei der kleinen Insel Salamis das so mächtige Asien zerbrachen, dienen jetzt den Römern, und über die Stadt, die einst Herrin Griechenlands war, verfügen jetzt die Weisungen aus Italien. (...) Tausende von anderen Völkern, erfüllt von tiefem Verlangen nach Freiheit, haben sich gebeugt; ihr allein haltet es für unwürdig, denen zu dienen, denen sich die Welt untergeordnet hat. Wie sieht das Heer und die Bewaffnung aus, auf die ihr vertraut? Wo ist bei euch die Flotte, die die römischen Meere in Besitz nehmen soll? Wo ist ein ausreichender Kriegsschatz für eure Unternehmungen? (...) Habt ihr denn gar keine Vorstellung von der Macht Roms und eurer eigenen Schwäche? Sind unsere Heere nicht oft auch schon den Nachbarvölkern unterlegen, während die Macht Roms auf der gesamten Erde unbesiegt blieb? Sie suchten sogar die Grenzen des Erdkreises noch zu überschreiten. (...) Wie steht es nun? Seid ihre reicher als die Gallier? Stärker als die Germanen? Klüger als die Griechen? Seid ihr zahlreicher als alle Völker der Erde? Was für ein Selbstvertrauen gibt euch den Mut, euch gegen die Römer zu erheben?““43

42 Vgl. SCHAEFER 1997, 170-179 über die antijüdischen Kontexte in Syrien und Palästina.

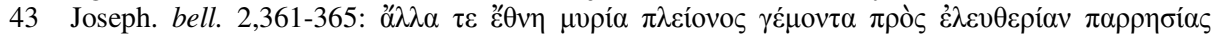

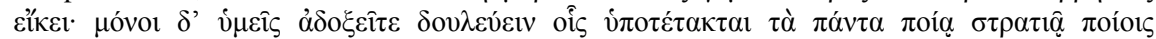

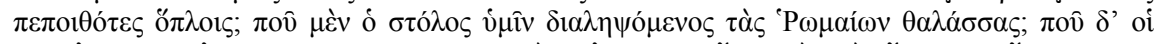

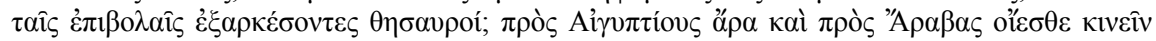

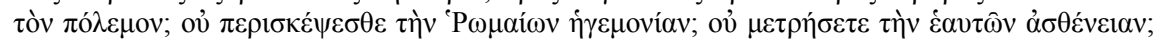

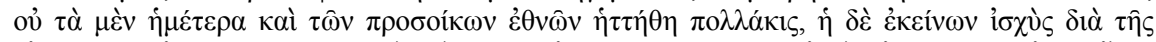

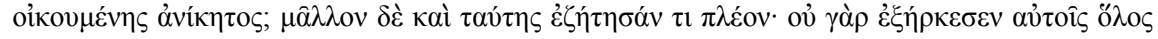


Der prophetische Charakter von Agrippas Rede spricht unbestreitbar für ihre $e x-$ eventu-Komposition. ${ }^{44}$ Doch gerade wenn es sich hierbei um ein Konstrukt des Josephus handelt, ${ }^{45}$ bestätigt dies nur die enorme Präsenz der Kategorie „Macht“ im griechischen Kontext. Josephus inszeniert in dieser Passage das stärkste Argument für Rom in der östlichen Welt. Eine explizite Erklärung dafür, warum der König damit bei der Jerusalemer Öffentlichkeit keinen dauerhaften Erfolg hatte, gibt der Historiker indessen nicht. Er deutet lediglich an, daß es die Religion gewesen sei, die die Akteure gegen das immunisierte, was Agrippa als vernünftig beschrieb. ${ }^{46}$ Und in der Tat kann angesichts des jüdischen Gottesverständnisses ein rein säkulares Machtargument aus mindestens zwei Gründen keine Valenz beanspruchen. Einerseits sorgte die transzendent ausgerichtete Normenbegründung im jüdischen Kontext ${ }^{47}$ dafür, daß innerweltlicher Opportunismus nicht der alleinige Maßstab für Entscheidungen im Konfliktfall sein konnte. Auf der anderen Seite ließ sich aus der unbestrittenen Annahme der Macht Jahwes leicht eine verführerische politische Option schmieden, getreu dem Motto: ,Wenn Gott für uns ist, wer kann dann gegen uns sein $?^{48}$ Zumindest die Radikalen, die Zeloten, haben mit der Verheißung göttlicher Unterstützung für die gerechte Sache Israels immer wieder Anhänger mobilisieren können. ${ }^{49}$ Für den Erfolg dieser Position spielte m.E. die Rezeption des siegreichen Aufstandes der Makkabäer gegen den Seleukidenkönig Antiochos IV. eine unheilvolle Rolle. ${ }^{50}$ In der jüdischen Tradition ist daran die Konfrontation zwischen illegitimer gottloser Macht und rechtgläubiger

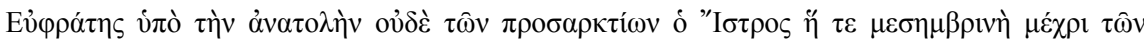

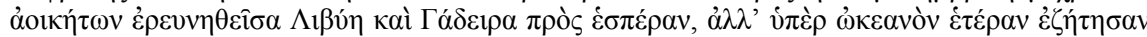

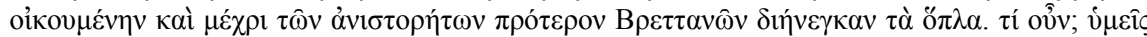

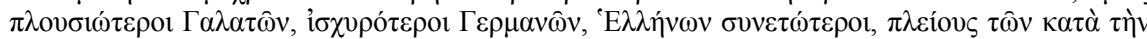

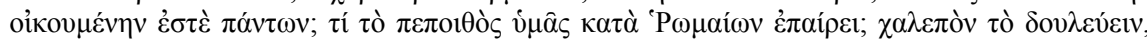

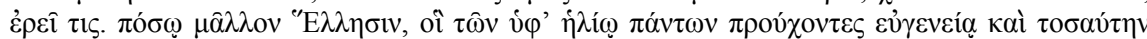

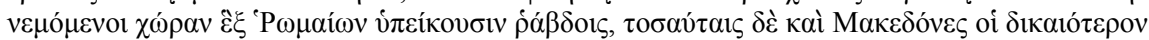

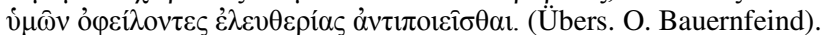

44 So wird in der Rede der Untergang des Judentums und die Zerstörung des Tempels imaginiert (Joseph. bell. 2,394-400).

45 Zu Form, Kontext und Bedeutung der Rede für Josephus' Werk: RAJAK 1991; MASON 2008, MASON 2008a, Abschnitt IV.

46 Nachdem Agrippa gemäß Josephus' Schilderung vorerst die Krise abzwenden konnte, gelang ihm dies wenig später nicht mehr. Die von der Kriegspartei formulierten Argumente läßt der Historiker allerdings nur in den Gegenargumenten der Friedenswilligen aufscheinen (Joseph. bell. 3, 408-417).

47 So markant HeNGEL 1976, v.a. 151-172; 229-234; TRAMPEDACH 2007, 61-65.

48 Diese Formulierung von Röm 8,31 basiert auf Jes 50,7-9 und 1Sam 14,6. Das Motiv findet sich einflußreich natürlich bereits im Buch Exodus.

49 TRAMPEDACH 2007, 40-48.

50 BRINGMANN 1983, 146-148; HENGEL 1976, bes. 38-48; s.a. MASON 2008a, Abschnitt IV mit dem Verweis darauf, daß Agrippa in seiner Rede bei Josephus das Vorbild des siegreichen Aufstandes bewußt klein redet, um das Unruhepotential in Palästina zu vermindern. 
nomineller Schwäche idealtypisch durchgespielt worden. Ich zitiere nur eine der vielen einschlägigen Stellen aus dem 1. Makkabäerbuch:

„Judas [Makkabäus] zog [dem syrischen Feldherrn Seron] mit ganz wenigen Männern entgegen. ${ }^{17}$ Als diese das Heer sahen, das gegen sie ausgerückt war, sagten sie zu Judas: Wie können wir mit so wenigen Leuten gegen eine solche Übermacht kämpfen? (...) ${ }^{18}$ Judas antwortete: Es kann leicht sein, daß viele wenigen in die Hände fallen; für den Himmel macht es keinen Unterschied, ob er durch viele oder wenige Rettung bringt. ${ }^{19}$ Denn der Sieg im Kampf liegt nicht in der Größe des Heeres, sondern in der Kraft, die vom Himmel kommt. ${ }^{20}$ Diese Leute da ziehen voll Hochmut und Bosheit (hybris kai anomia) gegen uns in den Kampf, um uns mit unseren Frauen und Kindern auszurotten und unsere Habe zu plündern. ${ }^{21}$ Wir aber kämpfen für unser < rechtes> Leben und für unsere Gesetze (psychai kai nomoi). ${ }^{22}$ Der Himmel wird sie vor unseren Augen vernichtend schlagen. Darum habt keine Angst vor ihnen! ${ }^{23}$ Kaum hatte er das gesagt, da stürzte er sich überraschend auf die Feinde, und Seron und sein Heer wurden vor seinen Augen aufgerieben." ${ }^{\text {(51 }}$

Die Botschaft, die diese Version des Kampfes der Makkabäer gegen die nichtjüdischen, verbrecherischen und sündigen Gegner Israels transportiert, ist unübersehbar: Wird für eine gerechte Sache gestritten, spielt die Macht des Feindes keine Rolle. Gott zählt mehr als die fehlenden Bataillone. Wenn dergleichen als Muster historischer Interpretation und als Maxime politischen Handelns gesellschaftsfähig wurde, war die Evidenz der römischen Ordnung strukturell aufgehoben.

\section{Diskurse der Gewalt}

Aus der imperialen Perspektive bildete das Christentum gewissermaßen die Potenzierung des jüdischen Problems. Immerhin waren die Juden eine präzis abgrenzbare Gruppe, die im Extremfall - dem kollektiven Aufruhr - das Objekt einer militärischen Operation sein konnte. Dagegen zeigte sich rasch, daß die

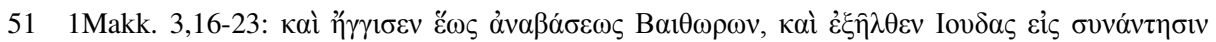

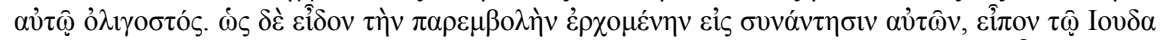

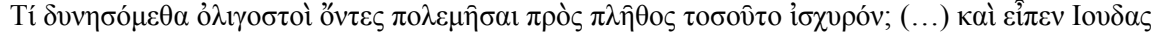

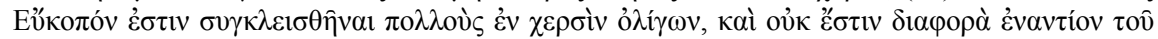

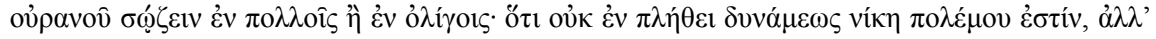

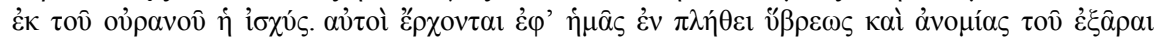

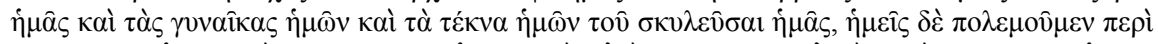

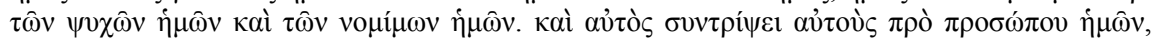

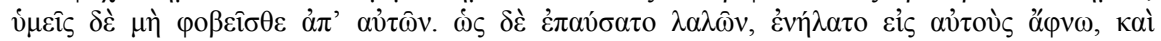

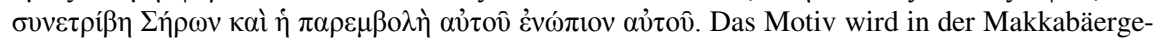
schichte häufig wiederholt, etwa 1 Makk 4,6-11; 4,28; 4,34. 
Gewaltfrage unter christlichen Auspizien eine unlösbare Aufgabe für das Imperium darstellte.

Die konkreten Probleme, die die Christianisierung für die traditionelle Ordnung aufwarf, beleuchtet der Ambrosius-Brief an Theodosius grell und exemplarisch: Sein Bündel von Argumenten für die Niederschlagung der KallinikonAffäre ist geradezu eine Blaupause der verfügbaren und eingesetzten Rechtfertigungen von Gewalt, die die klassischen Instrumente des Reiches aushöhlten und unterliefen. ${ }^{52}$ Entscheidend ist bereits der Parameter, den Ambrosius an die Auseinandersetzungen von 388 anlegt: Statt den Vorfall in Kallinikon als ordnungspolitische Aufgabe zu begreifen, die in der Tat ein Monopol des Kaisers wäre, etikettiert er sie als Glaubensfrage, die die exklusive Kompetenz des säkularen Herrschers überschreitet. ${ }^{53}$ In Ambrosius' Version der Ereignisse stehen sich nicht Gewaltopfer und Gewalttäter gegenüber, sondern die rechtgläubige Kirche Christi und die Synagoge, die er als „Heimstatt der Unfrommen und der Unvernunft, die Gott selbst verdammt habe“, apostrophiert. ${ }^{54}$ Die Wiederherstellung der zerstörten Synagoge durch den Bischof und aus den Mitteln der Kirche sei schon deshalb völlig undenkbar, weil dies den Triumph des gottlosen Konkurrenten und religiösen Gegners bedeutet hätte. ${ }^{55}$ Aus einer solchen, transzendent armierten Freund-Feind-Perspektive ist die Rechtsfrage irrelevant und die Ordnung des Reiches zweitrangig. Daß sich Ambrosius damit gegen die traditionellen imperialen Prinzipien wendet, ist ihm völlig bewußt, ja er formuliert das Problem ebenso offen wie brutal:

„Aber vielleicht ist es die Ordnung (disciplina), um die es dir zu tun ist, Kaiser. Doch was ist wichtiger? Die Durchsetzung der Ordnung oder die Sache der Religion? Es ist da allemal notwendig, dem Glauben nachzugeben".56

Ambrosius' Argument kulminiert in der Proklamation, er selbst würde bei Bedarf ebenso handeln wie der Bischof von Kallinikon und die Häuser der Gottlosen an-

52 Zur religiösen Rechtfertigung von Gewalt jetzt grundsätzlich GADDIS 2005, passim, bes. 21-22.

53 Ambr. epist. 74 (40),3 (epist. extr. coll. 1a,3): non ergo importunus indebitis me intersero, alienis ingero: sed debitis obtempero, mandatis Dei nostri obedio; s.a. epist. 40,5. Aus dieser Perspektive konsequent ist Ambrosius' Vorschlag, die Angelegenheit mit einem consilium von Bischöfen zu diskutieren: certe si mihi parum fidei defertur, jube adesse quos putaveris episcopos: tractetur, Imperator, quid salva fide agi debeat. Si de causis pecuniariis comites tuos consulis, quanto magis in causa religionis sacerdotes Domini aequum est consulas (epist.74 (40),27 (epist. extr. coll. 1a, 27).

54 Ambr. epist. 74 (40),9-15; Zitat 74 (40),14: non est ergo causa tantae commotioni idonea; ut propter aedificii exustionem in populum tam severe vindicetur: multo autem minus quia synagoga incensa est, perfidiae locus, impietatis domus, amentiae receptaculum, quod Deus damnavit ipse (Übers. U. Gotter).

55 Ambr. epist. 74 (40),10: (...) hunc titulum Iudaei in fronte synagogae suae scribent: templum impietatis factum de manubiis christianorum.

56 Ambr. epist. 74 (40),11: sed disciplinae te ratio, imperator, movet. Quid igitur est amplius? disciplinae species, an causa religionis? cedat oportet censura devotioni. 
zünden. ${ }^{57}$ Gottes Gebot stehe über den Gesetzen des Kaisers, lautet das mehrfach wiederholte Credo des Briefes. ${ }^{58}$

Indem Ambrosius die Vorgänge in Syrien zum legitimen religiösen Konflikt erklärt, kann er die kaiserliche Anordnung zur Wiedererrichtung der Synagoge als gefährlich für Kaiser und Reich stilisieren. Denn Theodosius ' Edikt mache den Bischof von Kallinikon entweder - wenn er nämlich tue, was der Kaiser verlange - zum Verräter an der Kirche oder - wenn er sich weigere - zum Märtyrer für seinen Glauben. Und auch für das administrative Personal, das mit der Durchführung des Edikts betraut werde, also den Comes orientis und die Soldaten, stelle sich im Prinzip die gleiche Alternative. Mit einem Befehl, der gegen die Maximen der Religion verstoße, riskiere Theodosius also die Aufkündigung des Gehorsams durch wesentliche Funktionsträger des Imperiums. In einem Glaubenskonflikt, so macht der Bischof unumwunden klar, bestehe kein regelhafter Anspruch des Kaisers auf Folgeleistung. ${ }^{59}$

Mit seiner Verschiebung der Parameter kann Ambrosius den Kaiser noch an einem anderen neuralgischen Punkt packen: an seiner eigenen Frömmigkeit. Immer wieder im Brief taucht das Motiv des gottesfürchtigen und zutiefst christlichen Herrschers auf. Daran knüpft sich ebenso oft die teils explizite, teils implizite Erwartung, ein solcher Protagonist des rechten Glaubens könne sich doch nicht - zumindest nicht in vollem Bewußtsein - eines Sakrilegs schuldig machen wie es die Begünstigung der jüdischen Christusfeinde wäre. ${ }^{60}$ Auch bei diesem Aspekt des bischöflichen Motivationsprogramms ist es vom wohlmeinenden Ratschlag bis zur unverhohlenen Drohung nur ein kleiner Schritt: Als Gegenbilder des frommen Herrschers bemüht Ambrosius den Apostatenkaiser Julian und den Usurpator Maximus, der, nachdem er ein energisches Edikt gegen das Anzünden einer Synagoge in Rom gerichtet hatte, im Nu und überall die bittersten Niederlagen erlitten habe. ${ }^{61}$ Indem der Bischof die Siege aufzählt, die Theodosius Gott verdanke, ${ }^{62}$ beschwört er somit gleichzeitig die Gefahr für den Kaiser, die göttliche Gnade durch unfromme Akte zu verlieren. Und beim Thema ,göttliche Gnade' angelangt, kann er auch das transzendente Potential der christlichen Religion in die Waagschale werfen. Denn schließlich, so Ambrosius, stehe in dieser Sache

57 Ambr. epist. 74 (40),8: Ambrosius rechtfertigt sich hier theologisch gewunden, weshalb er bislang die Synagoge von Mailand dennoch nicht angezündet habe.

58 Ambr. epist. 74 (40),2, wo er im Rückgriff auf das Alte Testament (Ezech 3,17-19) die Figur des von Gott eingesetzten Wächters bemüht, der die weltlichen Herrscher von Gottes Gebot in Kenntnis setzt, wenn er im Begriff steht zu sündigen; s.a. epist. 74 (40),3; 74 (40),8; 74 (40),2123; 74 (40),28: secundum homines loquor: caeterum plus hominibus Deus timetur, qui etiam imperatoribus iure praefertur. si amico aliquis, si parenti aut propinquo deferendum existimat, recte ego et deferendum Deo, et eum praeferendum omnibus iudicavi.

59 Ambr. epist. 74 (40),6-9; 74 (40), 18.

60 Ambr. epist. 74 (40),21-22.

61 Ambr. epist. 74 (40), 15; 74 (40),23.

62 Ambr. epist. $74(40), 22$. 
nicht nur das innerweltliche Schicksal des Kaisers auf dem Spiel: „Es ist eine ernste Sache“, schreibt er, „,dein Heil für die Juden zu gefährden.“63

An der Argumentation des Bischofs seinem Herrscher gegenüber ist für unsere Fragestellung wiederum nicht der zweifellos besonders rücksichtslose Ton interessant, sondern die Tatsache, daß es sich in der Sache um topische Muster und gerade nicht um Idiosynkrasien des Ambrosius gehandelt hat. Was er in der Kallinikon-Affäre vorbrachte, spiegelt vielmehr Positionen und Handlungsmaximen, die immer wieder wesentliche Optionen des christlichen Umgangs mit Heterodoxen und dem Phänomen der Gewalt bezeichnen. ${ }^{64}$ Wenn aber diese Axiome Plausibilität beanspruchen konnten, waren die beschriebenen Mechanismen imperialer Gewalthegung in der Tat prinzipiell außer Kraft gesetzt, die Neutralität der Institutionen ebenso wie die Macht des Reiches als Grundlage der Ordnung.

Erklärte man Gottes Gesetze - oder vielmehr die partikulare Auslegung davon - zum Maßstab für das eigene Handeln, wurde eine reichsweit verbindliche und wirksame Objektivierung von Richtig und Falsch unmöglich. Und mit der Kategorie des jenseitigen Heils griff auch der Terror nicht mehr, der das Rückgrat der Machtordnung des Reiches gewesen war und die Untertanen von allzu subjektiven Auslegungen abgehalten hatte. Die Entschlossenheit, notfalls für das ewige Leben sterben zu wollen, überforderte die Leistungsfähigkeit weltlicher Zwinggewalt in ihrem Kern. Aus dieser Perspektive war das sakralisierte Märtyrertum der christlichen Kirche die perfekte Negierung des Machtarguments. ${ }^{65}$ Den strukturellen Plausibilitätsverlust von Macht und Terror kann man in der Tat als Paradigmenwechsel begreifen.

Mindestens ebenso folgenreich für die Gewaltfrage war die neue persona des christlichen Kaisers seit Konstantin. Wenn der Herrscher eine - oder die zentrale - Rolle in der neuen religiösen Massenbewegung spielen wollte, durfte er sich den inhaltlichen Anforderungen des Glaubens nicht vollständig verschließen. ${ }^{66}$ Das galt natürlich auch für Normen und Konfliktkonstellationen, die das Christentum transportierte, und blieb naturgemäß nicht ohne Auswirkungen auf seine Haltung zur Gewalt. Denn sich als frommer Herrscher auf den Standpunkt zu stellen, die Gründe für Gewaltanwendung seien vollständig irrelevant für die Beurteilung des Vorgangs, ging kaum mehr an. Der Kampf für den rechten Glauben, für die Bekehrung Paganer etwa oder gegen den verderblichen Einfluß von Häretikern oder Juden durfte einfach nicht dasselbe sein wie gewöhnliches Brigantentum.

63 Ambr. epist. 74 (40), 25-26: grave est fidem tuam pro Iudaeis periclitari (26; Übers. U. Gotter).

64 Vgl. GADDIS 2005, 21-22; zum Einsatz von Gewalt und ihrer Rechtfertigung s. MCMULLEN 1984,86-101; zum „holy man“ als Anführer gewaltsamer Aktionen GADDIS 2005, 151-207.

65 Dazu BRown 1992, 64-65; DIEFENBACH 2000, 112-126, bes. 118-119; GADDIS 2005, 9; 35-45; zur Sorge staatlicher Institutionen, bei der Wiederherstellung der öffentlichen Ordnung Märtyrer zu schaffen GADDIS 2005, 220.

66 Vgl. DiEFENBACH, 1996; MEIER 2007. 
$\mathrm{Da} ß$ daraus ein ernstes Problem für die Autorität des Kaisers und die Stabilität des Imperiums erwachsen würde, war dem Archegeten der Allianz zwischen Christentum und römischem Staat sicherlich nicht bewußt gewesen. ${ }^{67}$ Als Konstantin der Große in das Christentum investiert hat, meinte er wohl durchaus, mit dem neuen privilegierten Kult ließe sich auch die römische Monarchie wirksam sanieren. ${ }^{68}$ Doch mußten die Herrscher des 4. Jahrhunderts bald erfahren, daß ihre zunehmend unausweichlicher werdende imago als christliche Kaiser sie zu Geiseln des religiösen Arguments machte. Der Fall Theodosius zeigt, daß dies je mehr galt, je orthodoxer und frommer ein Herrscher zu erscheinen versuchte. ${ }^{69}$

\section{Christliches Imperium und religiöser Konflikt}

Die christlichen Kaiser befanden sich in der Tat in einem unauflösbaren Dilemma: Einerseits konnten sie - ebensowenig wie ihre paganen Vorgänger - kein Interesse an dezentraler Gewaltanwendung und lokalen Unruhen haben. $\mathrm{Da}$ auch die Herrscher des 4. und 5. Jahrhunderts n. Chr. in diesen Fragen tatsächlich in traditionellen Bahnen dachten, zeigt eine Vielzahl an gesetzlichen Regelungen und Verwaltungsakten. ${ }^{70}$ Das galt auch und gerade für den Einsatz von Gewalt gegen Kultgruppen und ihre Gebäude, weil damit - zumal im Osten - kollektive Frontstellungen entstanden bzw. zementiert wurden, die wiederum rücksichtslos ausgetragene Konflikte auf lokaler Ebene endemisch machten. Auf der anderen Seite aber gab es im christianisierten Imperium kein wirksames Mittel und plausibles Ideologem mehr, um das Gefahrenpotential dieser Konstellation grundsätzlich in Schach zu halten. Gegen Brandstiftung mit religiösen Dogmen war man nahezu wehrlos. Und mehr noch: Die plausibelsten religiösen Konflikte, Gewaltanwendungen gegen Kultorte und Kultgruppen, wurden zur Speerspitze der Bewegung, die das römische Reich grundlegend und nachhaltig veränderte. ${ }^{71} \mathrm{Im}$ Windschatten der Auseinandersetzungen um die sakrale Topographie konnten religiöse Charismatiker und lokale kirchliche Würdenträger in Positionen einrücken, die ursprünglich auf die imperiale Zentrale bezogen waren. Es läßt sich

$67 \mathrm{Zu}$ den unvorhergesehenen Konflikten, die sich aus der staatlichen Involvierung in die christliche Religionspolitik ergaben vgl. POTTER 2004, 402-435; MITCHELL 2007, 276-295.

68 Es ist hier kaum der Ort, die Motive Konstantins für die Aufwertung des Christentums im Reichsverband und die Frage der persönlichen Glaubensüberzeugungen des Kaisers zu diskutieren (s. dazu mit einem Überblick über die aktuelle Forschung JUST 2003, 134-136). Daß die religionspolitischen Maßnahmen Konstantins neben allem anderen zumindest auch einen funktionalen Aspekt hatten, erscheint mir allerdings evident: s. dazu BLEICKEN 1992, 20-52; BRINGMANN 1995; JUST 2003 bes. 157-158; BERRENS 2004, 242 (aus der Perspektive des Solkultes); DRAKE 2000, 235-272; VAN DAM 2007, 293-309.

69 KOLB 1980, bes. 63-64.

70 S.o. n. 21.

71 S. hierzu HAHN - EMMEL - GOTTER 2008 und die anderen Beiträge im vorliegenden Band. 
zeigen, daß die Bischöfe zwischen dem 4. und dem 6. Jahrhundert Funktionen übernahmen, die früher von städtischen Beamten versehen wurden. ${ }^{72} \mathrm{Im}$ selben Zeitraum verschwinden die Repräsentanten der traditionellen zivischen Selbstverwaltung aus den Annalen, und dies ist wohl nicht nur eine Frage von Quellengattungen. Denn mit den religiösen Umwälzungen der Spätantike schwand die Basis ihrer sozialen und politischen Macht. Durch seine privilegierte Möglichkeit, die Menge über religiöse Inhalte - auch für gewaltsame Auseinandersetzungen zu mobilisieren, wuchs dem Bischof ein Instrument zu, das lokal und regional ohne Konkurrenz war. Besonders in den großen Städten des Ostens war damit Politik gegen den Führer der christlichen Gemeinschaft kaum mehr möglich. ${ }^{73}$ So war es im Grunde nur folgerichtig, daß dem Bischof seit dem 4. Jahrhundert schrittweise auch formale Kompetenzen übertragen wurden, die ihn zum eigentlichen Stadtherren machten. ${ }^{74} \mathrm{Da}$ dies wiederum die Art der Kommunikation zwischen der Zentrale und den lokalen Einheiten beeinflußte, liegt auf der Hand. Aus dieser Perspektive ist die religiöse Gewalt unter christlichen Auspizien der Katalysator des Neuen in den Städten des Imperiums.

Gewaltausübung im römischen Imperium war also durchaus ein struktureller Faktor der neuen Verbindung von Staat und Religion und damit der christlichen Religion in der Spätantike selbst. Mit dieser Feststellung, die sich als im Kern empirisch versteht, ist zwangsläufig die jüngst von Jan Assmann losgetretene Debatte um den Zusammenhang von Monotheismus und Gewalt evoziert. ${ }^{75}$ Kennzeichen der Kontroverse um die ,mosaische Unterscheidung', wie Assmann die religiös fundamentierte kategoriale Differenz zwischen ,Wahr' und ,Falsch' nennt, ${ }^{76}$ ist neben der großen Emotionalität, mit der sie geführt wird, die geringe Spezifität der verwendeten Kategorien: Monotheismus, Polytheismus, Gewalt, Toleranz sind allesamt Begriffe von großer und im einzelnen kaum kontrollierbarer Reichweite. Aus der Perspektive des Historikers ärgerlich ist dabei vor allem die Vermischung von heuristischen Ebenen, die vornehmlich theologische Artikel zu diesem Thema kennzeichnet: So ist die Frage nach den tatsächlichen gewaltsamen Konsequenzen des christlichen religiösen Diskurses natürlich unabhängig von der Frage nach der Notwendigkeit von Gewalt im Lichte der christlichen Glaubenssätze. Insbesondere die Argumentationsfigur, Gewalt sei nichts als

72 Vgl. dazu Brown 2002, 45-73; für Gallien JusSEN 1995, 673-713; zur Angleichung des äußeren Erscheinungsbildes der Bischöfe an die weltlichen Amtsträger s. HAENSCH 2003, 124-136.

73 HAHN 2004, bes. 276-280; ISELE 2008 (zu Alexandria).

74 BROWN 1992, 146-152, BAUMGART 1995; MARKSCHIES 1998, 451-469.

75 ASSMANN 2003 mit Diskussionsbeiträgen von Rolf Rendtorff (193-207), Erich Zenger (209220), Klaus Koch (221-238), Gerhard Kaiser (239-271), Karl-Josef Kuschel (273-286); s.a. Palmer 2007 sowie FÜRST, der das Thema Monotheismus und Gewalt in den letzten Jahren in einer ganzen Reihe von teilweise baugleichen Aufsätzen angegangen ist: 2004; $2006 \mathrm{a} ; 2007$.

76 ASSMANN 2003, bes. 28-37. 
ein „Mißbrauch“ der christlichen Religion, ${ }^{77}$ ein kontingenter Betriebsunfall also, transferiert die Diskussion vom deskriptiven in den normativen Bereich. Denn die Kategorie des „Mißbrauchs“ spiegelt einen emphatischen Begriff von der christlichen Religion, keinen analytischen. Zur Widerlegung der Relation zwischen Christianisierung und Gewaltanwendung taugt sie daher nicht. Nachdem Voltaires ,écrasez l'infâme' zurecht aus der Mode gekommen ist, sollte man sich allerdings vor allzu platten Gleichsetzungen hüten: So war Gewaltanwendung offenbar kein gleichmäßig präsentes Epiphänomen frühchristlicher religiöser Kommunikation. $\mathrm{Ob}$ es in den Kommunen des Reiches zu gewaltsamen Auseinandersetzungen kam oder nicht, hing entscheidend von der lokalen Konstellation ab. ${ }^{78}$ Religiöse Gewalt war e in e Handlungsoption - nicht mehr, aber auch nicht weniger. Und auch wenn sich nicht bestreiten läßt, daß es eine Korrelation zwischen Gewaltanwendung und Christianisierung gibt, läßt sich nicht ohne weiteres argumentieren, daß die neue monotheistische Religion der privilegierte Produzent von Gewalt im Imperium Romanum gewesen wäre. ${ }^{79}$ Denn schließlich war das Reich nicht gerade eine politische Idylle, ein Hort weltweiten friedlichen Miteinanders, sondern eine Ordnung, die nach Innen auf struktureller (sozialer) und angedrohter (politischer) Gewalt basierte und nach Außen seine Stabilität über zahlreiche Kriege und kontinuierlichen militärischen Terror aufrechterhielt.

Will man schiefe Verallgemeinerungen vermeiden, ist daher - eher als der Begriff des Monotheismus $-{ }^{80}$ der Begriff der Gewalt zu präzisieren, der meines Erachtens allzu amorph verwendet wird. Denn was sich mit der Christianisierung des Reiches verbinden läßt, ist wohl nicht so sehr die Zunahme von Gewalt insgesamt - eine übrigens schwer quantifizierbare Größe -, und auch nicht die gewaltsame Erschließung des potentiell religiösen Feldes insgesamt. So gab es wohl nur wenige gewaltsame Bekehrungen, ${ }^{81}$ und die Konstruktion auswärtiger Konflikte als Religionskriege war zumindest nicht sehr plausibel. Charakteristisch war dagegen die Zunahme einer ganz spezifischen Form von Gewalt, nämlich die des inneren Zwistes, der stasis. Gängige Aggregatszustände solcher Konflikte waren einerseits Auseinandersetzungen zwischen Christen und Paganen um heilige Orte, aber auch Kämpfe zwischen unterschiedlichen christlichen Bekenntnisgruppen und sogar - als Epiphänomene von Bischofsdoppelwahlen - innerhalb derselben

77 FÜRST 2004, 529-530; 2006, 338; 2006a, 79; 2007, 254; tendentiell auch Zenger bei ASSMANN 2003, 220. Bezeichnend für FÜRSTs Umgang mit der Debatte sind Verharmlosungen, etwa die Überschrift in 2006, 63: „Christliche Schwierigkeiten mit religiöser Pluralität“; ähnlich 2006, 60: „Aus dem Gesagten ergibt sich, daß bei der Christianisierung der Spätantike die Anwendung von Gewalt zwar nicht selten bezeugt ist, aber keine zentrale Rolle spielte (...).

78 Hierin liegt ein ganz wesentlicher Ertrag der Arbeit von Johannes HAHN (2004, pointiert 292294).

79 Zur urbanen Gewalt in der Spätantike als Breitenphänomen s. etwa GREGORY 1983, 138-147; zum Phänomen des religiösen Konflikts: 147-155.

80 Etwa FÜRST 2005.

81 Vgl. FÜRST 2006, 50-59. 
konfessionellen Gruppe. ${ }^{82}$ Katalysatoren des Gewalteinsatzes im Innern waren in der Regel symbolische Akte wie Angriffe auf Kultstätten, die Verhöhnung sakraler Güter sowie Prozessionen durch die Wohngebiete der jeweiligen heterodoxen Gemeinschaft. $^{83}$

Aus imperialer Perspektive bedeuteten Praktiken dieser Art einen schwer zu überschätzenden Einschnitt. Denn offenbar wurden mit der Christianisierung des Imperiums Konflikte, deren gewaltsame Austragung von der römischen Administration über Jahrhunderte gehegt bzw. unterdrückt worden waren, wieder führbar. Im christlich-religiösen Diskurs fand die Konkurrenz zwischen dem lokalen Führungspersonal erneut stabile und binäre Kristallisationspunkte, um die sich eine gewaltbereite Gefolgschaft organisieren ließ ${ }^{84}$ Zugespitzt könnte man formulieren, daß die östlichen Gemeinschaften unter christlichen Auspizien zu ihrer konfliktuellen Identität vor dem römischen Imperium zurückfanden. Aus diesem Blickwinkel wäre die religiöse Gewalt nicht Katalysator des Neuen, sondern die Restauration älterer kultureller Praktiken im neuen Gewand. Von dieser Zäsur war jedoch nicht nur das Zusammenleben der heterodoxen Gruppen im Reich betroffen, sondern auch das Verhältnis des Kaisers zu seinen Untertanen insgesamt. Weit davon entfernt, das monarchische System automatisch zu stärken, ${ }^{85}$ waren Frömmigkeit und christlicher Glaube ein neues Feld, auf dem sich der Herrscher zu beweisen hatte, auf dem er Akzeptanz gewinnen, aber in mindestens gleichem Maße auch verlieren konnte. Denn was fromm und rechtgläubig war, darüber gab es reichsweit durchaus verschiedene Auffassungen, und es zeigte sich rasch, daß der Kaiser keine probaten Mittel besaß, die eigene dogmatische Position, wenn er denn eine hatte, auf breiter Front durchzusetzen. Das heißt aber konkret, daß dem Herrscher der Gehorsam auch ganz handgreiflich aufgekündigt werden konnte. ${ }^{86}$ In dieser Sache gab es für die Zentrale keinen Königsweg. Am ehesten noch ließ sich die eigene Herrschaft imprägnieren, indem der Kaiser selbst den religiösen Diskurs zu besetzen suchte und eine orthodoxe persona pflegte. ${ }^{87}$ Besonderer Ausweis davon waren die markante Anti-Paganen- und Anti-Häretiker-Gesetzgebung ${ }^{88}$ bereits der Söhne Konstantins, vor allem aber der Kaiser seit Theodosius I. Spätestens an diesem Punkt verwickelte sich der Herrscher indessen notwendigerweise in Inkohärenzen zwischen formaler Ordnungs-

82 Alle diese Varianten treten etwa in der Geschichte Antiocheias im 4. Jahrhundert zutage (s. HAHN 2004, 121-189).

83 S. HAHN 2008; ISELE 2008.

84 BROWN 1998, 643-651 und vor allem LiM 1963, passim, der zeigt, wie intellektuelle theologisch-philosophische Positionen durch ihre Implantierung ins Feld des allgemeinen Glaubens ganz unmittelbar politische Wirkung entfalten und zur Mobilisierung von militanten Anhängern taugen; s.a. GOTTER 2003, 205-211 für ein lokales Biotop.

85 So aber FOWDEN 1993.

86 GADDIS 2005, 151-207.

87 MEIER 2007 (für Theodosius II.) und MEIER 2003 (zu Justinian).

88 S. NOETHLICHS 1986, 1155-1176; 1182-1190. 
politik und materiell-dogmatischer Religionspolitik: Eine glaubwürdige Neutralität ließ sich in der Konsequenz kaum noch behaupten. Die Frage nach der Rechtgläubigkeit war für den Herrscher damit endgültig zum Bezugspunkt seiner Macht und die neue Religion zur Grammatik des soziopolitischen Systems geworden. ${ }^{89}$

Versucht man vor diesem Hintergrund abschließend die Veränderung des Verhältnisses von Religion und Politik in der Spätantike auf den Punkt zu bringen, könnte man auf den ersten Blick meinen, in der Ausweitung des religiösen Feldes das Signum des Zeitalters zu sehen. Doch angesichts der früheren ubiquitären Präsenz ,paganer', polytheistischer Religionsübung erscheint dies kaum haltbar. Denn gerade in den lokalen Kulturen des Reiches ebenso wie auf imperialer Ebene waren religiöse Handlungen im politischen und sozialen Leben der vorchristlichen Zeit gerade omnipräsent. Die Idee eines religionsfreien politischen Raumes stand daher auch in vorchristlicher Zeit nicht zur Verfügung. Wozu man pagane Kulte allerdings nicht nutzen konnte, war die Produktion, Anstachelung und Organisation von inneren Konflikten. Die Logik der paganen Religion war auf die Herstellung von kollektiver Einheit gerichtet, nicht auf Dissoziation. Unter diesen Umständen scheint sich mir das Verhältnis von Politik und Religion in der Spätantike wesentlich dadurch zu verschieben, daß die christliche Religion ein konkurrenzlos effizientes Medium des inneren Konflikts war. Diese konfliktuelle Potenz des Christentums bei gleichzeitiger starker Präsenz religiöser Akte hatte eine enorm expansive Tendenz. Denn es läßt sich zeigen, daß seit dem 4. Jahrhundert sämtliche denkbaren Auseinandersetzungen als Auseinandersetzungen zwischen unterschiedlichen religiösen Positionen und Gruppen verstehbar und inszenierbar waren. Diese Beobachtung hat meines Erachtens wiederum unvermeidliche Konsequenzen für eine praktikable Definition von ,religiösem Kon-

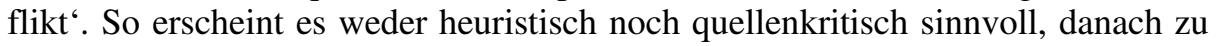
fragen, ob es bei dieser oder jener Auseinandersetzung um eine ,wirklich religiöse' Sache gegangen sei oder ob man die Religion lediglich vorgeschoben habe. Da der Historiker an die individuelle Psyche der spätantiken Akteure nicht mehr herankommt, ist eine essentialistische Unterscheidung zwischen einer genuin religiösen Überzeugung und einer lediglich sekundären religiösen Intention nicht zu treffen und sollte daher - als heuristischer Irrealis - auch nicht das Ziel der Analyse bilden. Verläßlichere Größen sind dagegen kollektive Handlungen und ihre kommunikativen Voraussetzungen. Wenn man akzeptiert, daß sich Gewalt unter christlichen Auspizien - entgegen der imperialen Tradition - religiös legitimieren ließ, sollte man konsequenterweise jede Auseinandersetzung, in der die Parteiungen mit religiösen Argumenten mobilisiert wurden, als religiösen Konflikt oder Religionskrieg ${ }^{90}$ verstehen. Auf dieser Ebene läßt sich Geschehen wohl

89 Vgl. grundsätzlich DIEFENBACH 1996.

90 Es ist im Grunde erstaunlich, daß eine Theorie des religiösen Konflikts, zumindest im Rahmen der empirisch arbeitenden Geschichtswissenschaft, weitgehend unterdeterminiert bleibt - selbst 
noch weitgehend einvernehmlich beschreiben. Jenseits der kommunikativen Oberfläche sozialen Handelns allerdings beginnt rasch die rekonstruktive Willkür.

für Epochen, die traditionell mit den entsprechenden Begrifflichkeiten arbeiten. Dies mag auch damit zusammenhängen, daß in der modernen Konfessionalisierungsforschung der religiöse Konflikt eher als Generator und Subsystem von Staatenbildungsprozessen analysiert wird (s. etwa BURCKHARDT 1997, bes. 548-555). Wie wenig befriedigend der Diskusionsstand ist, zeigen etwa die Versuche Konrad REPGENs, die Natur eines Religionskrieges bzw. religiösen Konflikts in der frühen Neuzeit gleichsam legalistisch über die normativen und öffentlichen Rechtfertigungen des Konfliktbeginns zu definieren (REPGEN 1985; 1987). Dieses Unternehmen bleibt weitgehend im Terminologischen stecken, was REPGEN im übrigen selbst sieht, wenn er den Straßburger Historiker und Juristen des 17. Jahrhunderts, Johann Heinrich Boecler, zustimmend in dem Sinne zitiert, daß sehr zwischen Begründung und Motiv zu unterscheiden sei $(1985,46)$. 


\section{Literaturverzeichnis}

Assmann, J., Die Mosaische Unterscheidung oder der Preis des Monotheismus, München - Wien 2003.

Baltrusch, E., Die Juden und das Römische Reich. Geschichte einer konfliktreichen Beziehung, Darmstadt 2002.

Barrett, J.C., Romanization. A Critical Comment, in: D.J. Mattingly (Hrsg.), Dialogues in Roman Imperialism. Power, Discourse, and Discrepant Experience in the Roman Empire, Portsmouth 1997, 51-64.

Baumgart, S., Die Bischofsherrschaft im Gallien des 5. Jahrhunderts. Eine Untersuchung zu den Gründen und Anfängen weltlicher Herrschaft der Kirche, München 1995.

Bendlin, A., Eine Zusammenkunft um der religio willen ist erlaubt..."? Zu den politischen und rechtlichen Konstruktionen von (religiöser) Vergemeinschaftung in der römischen Kaiserzeit, in: H.G. Kippenberg - G.F. Schuppert (Hrsg.), Die verrechtlichte Religion. Der Öffentlichkeitsstatus von Religionsgemeinschaften, Tübingen 2005, 65107.

Benvicenni, A., Progetti di riforme costituzionali nelle epigrafiche greche dei secoli IV-II a.C., Bologna 2003.

Berrens, St., Sonnenkult und Kaisertum von den Severern bis zu Constantin I. (193-337 n. Chr.), Stuttgart 2004.

Bleicken, J., Constantin der Große und die Christen. Überlegungen zur konstantinischen Wende, München 1992.

Brenk, B., Die Umwandlung der Synagoge von Apamea in eine Kirche. Eine mentalitätsgeschichtliche Studie, in: Tesserae. Festschrift J. Engemann, Münster 1991, 1-25.

Bringmann, K., Hellenistische Reform und Religionsverfolgung in Judäa, Göttingen 1983.

Bringmann, K., Die konstantinische Wende. Zum Verhältnis von politischer und religiöser Motivation, Historische Zeitschrift 260 (1995), 21-47.

Brown, P., Power and Persuasion in Late Antiquity. Towards a Christian Empire, Madison 1992.

Brown, P., Christianization and Religious Conflict, in: A. Cameron - P. Garnsey (Hrsg.), The Cambridge Ancient History XIII: The Late Empire A.D. 337-425, Cambridge 1998, 632-664.

Brown P., Poverty and Leadership in the Later Roman Empire, Hanover 2002.

Burckhardt, J., Die Friedlosigkeit der frühen Neuzeit. Grundlegung einer Theorie der Bellizität Europas, in: Zeitschrift für historische Forschung 24 (1997), 509-574.

Cartledge, P., The Greeks. A Portrait of Self and Others, Oxford 1993.

Dahlheim, W., Geschichte der römischen Kaiserzeit, München ${ }^{3} 2003$.

Deininger, J., Der politische Widerstand gegen Rom in Griechenland 217-86 v. Chr., Berlin - New York 1971.

Diefenbach, St., Frömmigkeit und Kaiserakzeptanz im frühen Byzanz, Saeculum 47 (1996), 35-66.

Diefenbach, St., Jenseits der „Sorge um sich“. Zur Folter von Philosophen und Märtyrern in der römischen Kaiserzeit, in: P. Burschel u.a., Das Quälen des Körpers. Eine historische Anthropologie der Folter, Köln u. a. 2000, 99-131.

Dössel, A., Die Beilegung innerstaatlicher Konflikte in den griechischen Poleis vom 5.-3. Jahrhundert v. Chr., Frankfurt/M. 2003. 
Fowden, G., Bishops and Temples in the Eastern Roman Empire A.D. 320-435, JThS (1978), 53-78.

Fowden, G., Empire to Commonwealth. Consequences of Monotheism in Late Antiquity, Princeton 1993.

Fürst, A., Monotheismus und Gewalt. Fragen an die Frühzeit des Christentums, in: Stimmen der Zeit 222 (2004), 521-531.

Fürst, A., Christentum im Trend. Monotheistische Tendenzen in der späten Antike, in: Zeitschrift für antikes Christentum 9 (2005), 496-523.

Fürst, A., Monotheismus und Monarchie. Zum Zusammenhang von Heil und Herrschaft in der Antike, in: Theologie und Philosophie 81 (2006), 321-338.

Fürst, A., Friedensethik und Gewaltbereitschaft. Zur Ambivalenz des christlichen Monotheismus in seinen Anfängen, in: A. Fürst (Hrsg.), Friede auf Erden? Die Weltreligionen zwischen Gewaltverzicht und Gewaltbereitschaft, Freiburg u.a. 2006a, 45-81. 188-196.

Fürst, A., Wahrer Gott - wahre Gerechtigkeit. Politische Implikationen des Monotheismus in der Spätantike, in: G. Palmer (Hrsg.), Fragen nach dem einen Gott. Die Monotheismus-Debatte im Kontext, Tübingen 2007, 251-282.

Gaddis, M., There is No Crime for Those Who Have Christ. Religious Violence in the Christian Roman Empire, Berkeley u.a. 2005.

Garnsey, P., The Criminal Jurisdiction of Governors, JRS 58 (1968), 51-59.

Gehrke, H.-J., Stasis. Untersuchungen zu den inneren Kriegen in den griechischen Staaten des 5. und 4. Jahrhunderts v. Chr., München 1985.

Gehrke, H.-J., Die Griechen und die Rache. Ein Versuch in historischer Psychologie, Saeculum 38 (1987), 121-149.

Gehrke, H.-J., Geschichte des Hellenismus, München ${ }^{3} 2003$.

Gotter, U., Thekla gegen Apoll. Überlegungen zur Transformation regionaler Sakraltopographie in der Spätantike, Klio 85 (2003), 189-211.

Gotter, U., Fundamental Differences and Cross-Cultural Contact. The Semantics of Power in Greece and Rome, Harvard Studies in Classical Philology 2008, 179-230.

Goodman, M., Opponents of Rome: Jews and Others, in: in: L. Alexander (Hrsg.), Images of Empire, Sheffield 1991, 222-238.

Gregory, T.E., Urban Violence in Late Antiquity, in: R.T. Marchese (Hrsg.), Aspects of Graeco-Roman Urbanism, Oxford 1983, 138-161.

Groß-Albenhausen, K., Imperator Christianissimus. Der christliche Kaiser bei Ambrosius und Johannes Chrysostomus, Frankfurt/M. 1999.

Haensch, R., Römische Amtsinhaber als Vorbilder für die Bischöfe des 4. Jahrhunderts?, in: L. de Blois - P. Erdkamp - O. Hekster - G. de Kleijn - St. Mols (Hrsg.), The Representation and Perception of Roman Imperial Power. Proceedings of the Third Workshop of the International Network Impact of Empire (Roman Empire, c. 200 B.C.-A.D. 476), Amsterdam 2003, 117-136.

Hahn, J., Gewalt und religiöser Konflikt. Studien zu den Auseinandersetzungen zwischen Christen, Heiden und Juden im Osten des Römischen Reiches (von Konstantin bis Theodosius II.), Berlin 2004.

Hahn, J., The Conversion of the Cult Statues: The Destruction of The Serapeion and the Transformation of Alexandria into the 'Christ-Loving' City, in: J. Hahn - St. Emmel - U. Gotter (Hrg.), From Temple to Church. Destruction and Renewal of Local Cultic Topography in Late Antiquity, Leiden 2008, 335-365. 
Hahn, J. - Emmel, St., - Gotter, U. (Hrsg.), From Temple to Church. Destruction and Renewal of Local Cultic Topography in Late Antiquity, Leiden 2008.

Halfmann, H., Die Selbstverwaltung der kaiserzeitlichen Polis in Plutarchs Schrift Praecepta gerendae rei publicae, Chiron 32 (2002), 83-95.

Hansen, M.H., The Athenian Democracy in the Age of Demosthenes. Structures, Principles and Ideology, Oxford 1991.

Heather, P., The Fall of the Roman Empire, London 2005.

Hengel, M., Die Zeloten. Untersuchungen zur jüdischen Freiheitsbewegung in der Zeit von Herodes I. bis 70 n. Chr., Leiden - Köln ${ }^{2} 1976$.

Hengel, M., Jerusalem als jüdische und hellenistische Stadt, in: M. Hengel, Judaica, Hellenistica et Christiana. Kleine Schriften II, Tübingen 1999, 115-156.

Horstkotte, H.-J., Die Strafrechtspflege in den Provinzen der römischen Kaiserzeit zwischen hegemonialer Ordnungsmacht und lokaler Autonomie, in: W. Eck (Hrsg.), Lokale Autonomie und römische Ordnungsmacht in den kaiserzeitlichen Provinzen vom 1. bis 3. Jahrhundert, München 1999, 303-318.

Isele, B., Religiöse Gewalt, heiliger Raum und christliche Topographie in Alexandria und Konstantinopel (4. Jh.), Münster 2008.

Jacques, F. - Scheid, J., Rom und das Reich in der Hohen Kaiserzeit 44 v. Chr. $-260 n$. Chr., Bd. I: Die Struktur des Reiches, Leipzig 1998.

Jördens, A., Das Verhältnis der römischen Amtsträger in Ägypten zu den „Städten“ in der Provinz, in: W. Eck (Hrsg.), Lokale Autonomie und römische Ordnungsmacht in den kaiserzeitlichen Provinzen vom 1. bis 3. Jahrhundert, München 1999, 141-180.

Jussen, B., Über ,Bischofsherrschaften' und die Prozeduren politisch-sozialer Umordnung in Gallien zwischen ,Antike' und ,Mittelalter', in: Historische Zeitschrift 260 (1995), 673-718.

Just, P., Imperator et Episcopus. Zum Verhältnis von Staatsgewalt und christlicher Kirche zwischen dem 1. Konzil von Nicaea (325) und dem 1. Konzil von Konstantinopel (381), Stuttgart 2003.

Juster, J., Les juifs dans l'Empire Romain. Leur condition juridique, économique et sociale, 2 Bde., New York 1914.

Kolb, F., Der Bußakt von Mailand: Zum Verhältnis von Staat und Kirche in der Spätantike, in: Geschichte und Gegenwart. Festschrift K.D. Erdmann, Neumünster 1980, 4174.

Lendon, J.E., Empire of Honour. The Art of Government in the Roman World, Oxford 1997.

Lim, R., Public Disputation, Power, and Social Disorder in Late Antiquity, Berkeley Los Angeles - London 1995.

Linder, A., The Jews in Roman Imperial Legislation, Jerusalem 1987.

Lintott, A., Violence, Civil Strife and the Revolution in the Classical City 750-330 BC, London - Canberra 1982.

Markschies, Chr., Die politische Dimension des Bischofsamtes im vierten Jahrhundert, in: J. Mehlhausen (Hrsg.), Recht-Macht - Gerechtigkeit, Gütersloh 1998, 438-469.

Mason, St., Excursus II: The Deliberative Speech of Agrippa II, in: S. Mason (Hrsg.), Flavius Josephus: Translation and Commentary, vol. 1b: The Judean War, Leiden 2008 (im Druck).

Mason, St., The Greeks and the Distant Past in Josephus' Judean War, in: G. Gardner - K. Osterloh (Hrsg.), Antiquity in Antiquity, Stuttgart 2008a (im Druck). 
Mattingly, D.J., Dialogues of Power and Experience in the Roman Empire, in: D.J. Mattingly (Hrsg.): Dialogues in Roman Imperialism. Power, Discourse, and Discrepant Experience in the Roman Empire, Portsmouth 1997, 7-26.

McLynn, N.B., Ambrose of Milan. Church and Court in a Christian Capital, Berkeley Los Angeles - London 1994.

McMullen, R., Christianizing the Roman Empire (A.D. 100-400), New Haven - London 1984.

Meier, M., Das andere Zeitalter Justinians. Kontingenzerfahrung und Kontingenzbewältigung im 6. Jahrhundert n.Chr., Göttingen 2003.

Meier, M., Die Demut des Kaisers. Aspekte der religiösen Selbstinszenierung bei Theodosius II. (408-450), in: A. Pecar - K. Trampedach (Hrsg.), Die Bibel als politisches Argument. Voraussetzungen und Folgen biblizistischer Herrschaftslegitimierung in der Vormoderne, München 2007, 135-158.

Meyer-Zwiffelhoffer, E., Politikos archein. Zum Regierungsstil der senatorischen Statthalter in den kaiserzeitlichen griechischen Provinzen, Stuttgart 2002.

Mitchell, St., A History of the Later Roman Empire AD 284-641: The Transformation of the Ancient World, Oxford u.a. 2007.

Noethlichs, K.-L., Die gesetzgeberischen Maßnahmen der christlichen Kaiser des vierten Jahrhunderts gegen Häretiker, Heiden und Juden, Köln 1971.

Noethlichs, K.-L., Heidenverfolgung, in: RAC 13 (1986), 1149-1190.

Nörr, D., Imperium und Polis in der hohen Prinzipatszeit, München 1966.

Nörr, D., Zu den Xenokriten (Rekuperatoren) in der römischen Provinzialgerichtsbarkeit, in: W. Eck (Hrsg.), Lokale Autonomie und römische Ordnungsmacht in den kaiserzeitlichen Provinzen vom 1. bis 3. Jahrhundert, München 1999, 257-302.

Palmer, G., Einleitung: Die 'Realität' des Monotheismus' als politisches Problem der Kulturwissenschaften, in: G. Palmer (Hrsg.), Fragen nach dem einen Gott. Die Monotheismus-Debatte im Kontext, Tübingen 2007, 1-22.

Potter, D.S., The Roman Empire at Bay AD 180-395, London - New York 2004.

Rabello, A.M.R., The Legal Condition of the Jews in The Roman Empire, in: ANRW II 13, Berlin 1980, 662-762.

Rajak, T., Friends, Romans, Subjects: Agrippa II's Speech in Josephus's Jewish War, in: L. Alexander (Hrsg.), Images of Empire, Sheffield 1991, 122-134.

Repgen, K., Kriegslegitimation in Alteuropa. Entwurf einer historischen Typologie, in: Historische Zeitschrift 241 (1985), 27-49.

Repgen, K., What is a ,Religious War', in: E.I. Kouri - T. Scott (Hrsg.), Politics and Society in Reformation Europe. Essays for Sir Geoffrey Elton on his Sixty-Fifth Birthday, Basingstoke 1987, 311-328.

Rilinger, R., Humiliores - Honestiores. Zu einer sozialen Dichotomie im Strafrecht der römischen Kaiserzeit, München 1988.

Safrai, S., Das Zeitalter der Mischna und des Talmuds (70-640), in: H.H. Ben Sasson (Hrsg.), Geschichte des jüdischen Volkes. Von den Anfängen bis zur Gegenwart, München ${ }^{3} 1994,377-470$.

Sartre, A. - Sartre, M., Notables en conflit dans le monde Grec sous le Haut-Empire, Cahiers d'histoire 45 (2000), 507-532.

Schaefer, P., Judeophobia. Attitudes Towards the Jews in the Ancient World, Cambridge/Mass. 1997. 
Stahl, M., Imperiale Herrschaft und provinziale Stadt. Strukturprobleme der römischen Reichsorganisation im 1.-3. Jh. der Kaiserzeit, Göttingen 1978.

Stemberger, G., Juden und Christen im Heiligen Land. Palästina unter Konstantin und Theodosius, München 1987.

Swain, S., Hellenism and Empire. Language, Classicism, and Power in the Greek World, AD 50-250, Oxford 1996.

Trampedach, K., Die Tyrannis als Wunsch- und Schreckbild, in: B. Seidensticker - M. Vöhler (Hrsg.), Gewalt und Ästhetik. Zur Gewalt und ihrer Darstellung in der griechischen Klassik, Berlin - New York 2006, 3-27.

Trampedach, K., Die Hasmonäer und das Problem der Theokratie, in: A. Pečar - K. Trampedach (Hrsg.), Die Bibel als politisches Argument. Voraussetzungen und Folgen biblizitischer Herrschaftslegitimierung in der Vormoderne, München 2007, 3765.

Trombley, F.R., Hellenic Religion and Christianization, C.370-529, 2 Bde., Leiden u.a. 1993/1994.

van Dam, R., The Roman Revolution of Constantine, Cambridge 2007.

Mattingly, D.J. (Hrsg.), Dialogues in Roman Imperialism. Power, Discourse, and Discrepant Experience in the Roman Empire, Portsmouth 1997

Wilker, J., Für Rom und Jerusalem. Die herodianische Dynastie im 1. Jahrhundert n. Chr., Frankfurt/M. 2007.

Wolff, H., ,Administrative Einheiten' in den Nordprovinzen und ihre Beziehungen zu römischen Funktionsträgern, in: W. Eck (Hrsg.), Lokale Autonomie und römische Ordnungsmacht in den kaiserzeitlichen Provinzen vom 1. bis 3. Jahrhundert, München 1999, 47-60. 